\title{
Acoustic Directivity and Detectability of Electric Powered Two-Wheelers
}

\author{
Pedro Poveda-Martínez ${ }^{1)}$, Ramón Peral-Orts ${ }^{2)}$, Nuria Campillo-Davo ${ }^{2)}$, Hector Campello-Vicente ${ }^{2)}$, \\ Jaime Ramis-Soriano ${ }^{1)}$ \\ 1) Applied Acoustics Group, University Institute of Physics Applied to Sciences and Technologies, \\ University of Alicante, 03690 San Vicente del Raspeig, Alicante, Spain. pedro.poveda@ua.es \\ 2) Mechanical Engineering and Energy Department, Miguel Hernández University of Elche, \\ 03202 Elche, Alicante, Spain
}

\begin{abstract}
Summary
Since motorcycles are one of the main sources of noise in urban environments, the use of electric powered two-wheelers may contribute to the improvement of soundscapes in Smart Cities. However, quiet vehicles can lead to an increased risk of accident for pedestrians and other drivers. In order to assess the noise generated by powered two-wheelers and their detectability five different low capacity motorcycles were measured in a pass-by noise test. The measurements were performed at different speeds using a linear microphone array and a dummy head. The sound directivity radiated by the moving sources was studied with a microphone array. To establish the detectability of powered two-wheelers, thirty-seven subjects participated in an auditory test consisting on a virtual road-crossing scenario. The subjects had to detect the approaching of a vehicle at $20 \mathrm{~km} / \mathrm{h}$. The results showed a significant reduction in the sound pressure level emitted by electric motorcycles at low-speed, as well as a notable increase in sound directivity with velocity. The reaction time obtained for the detection of electric powered two-wheelers was higher compared to the traditional propulsion ones. The results highlighted the risk posed by this kind of electric vehicles for pedestrians.
\end{abstract}

PACS no. 43.50.Lj, 43.50.Rq

\section{Introduction}

The use of electric engines has been a significant change in the acoustic behaviour of vehicles. This has encouraged the scientific community to explore this propulsion system, analysing the validity of the current noise, vibration and harshness (NVH) prediction and characterization tools. In accordance with [1], 20 million electric vehicles (EV) were estimated all over the world in 2020. Prospects have been reduced due to the high price of batteries and the global economic situation. At the end of 2014 there were about 665,000 electric four-wheel passenger vehicles, which represents a $0.08 \%$ of the total vehicles. Attention should also be drawn to the existing stock in China, with 230 million of e-bikes and 36,500 e-buses [2].

Electric vehicles represent a significant reduction of environmental pollution in cities. The decrease of the gases emitted by this kind of vehicle is a clear advantage compared with the traditional vehicles. Moreover, the decrease of vibrations provided by the engine due to the absence of reciprocating and rotational masses inside, can lead to a considerably decrease of noise. In general, EVs are powered by DC batteries. The voltage provided by the cells

Received 28 August 2016, accepted 5 September 2017. is transformed into a magnitude and frequency controlled AC signal by means of an inverter using pulse-with modulation (PWM). The switching frequency to generate the PWM, together with the magnet noise from the electric powertrain, are two of the main contributions to the noise emitted by EVs. The fans used for batteries may be considered as another source of noise in EVs. The decrease of the sound pressure level emitted by EVs in comparison with internal combustion engine vehicles (ICEV) is clearly evident at speeds below $50 \mathrm{~km} / \mathrm{h}$. In this case, the global noise from the vehicle is dominated by the sound produced by the propulsion system. At speeds above $50 \mathrm{~km} / \mathrm{h}$, the noise generated by the tyre-road contact and the aerodynamics of the vehicle becomes more important. At this situation, the noise emitted by EVs and ICEVs matches as illustrated in [3]. The study compares the sound pressure level generated by different vehicles depending on the speed. Similar results were obtained in $[4,5]$ comparing different propulsion systems.

The reduction of noise may have a positive impact in health terms, since nearly 20,000 people die each year because of disease resulting from noise [6]. The use of EVs may significantly change the soundscapes in urban environments. However, quiet vehicles constitute a disadvantage from the road safety point of view. Since EVs are more complicated to detect, the risk of an accident in- 
creases for pedestrians, cyclists and other road users. L. Garay et al. in [7] show the increase in the pedestrian response time in the presence of an EV and similar results are obtained in [8]. According to [9], a hybrid electric vehicle (HEV) is twice more likely to be involved in a pedestrian crash than an internal combustion engine vehicle in the same situation. In order to improve the detectability of four-wheel EVs, some government administrations have established the need of an Acoustic Vehicle Alerting System (AVAS) into the vehicles. These systems may emit sounds, under some speed conditions, to alert pedestrians of the presence of a vehicle without increasing the environmental noise pollution. The use of these devices has already been discussed in the literature. K. Yamauchi compares in [10] the level of different warning sounds to be detected in a number of urban background noises. E. Parizet et al. study in [11] the detectability of different designed warning sounds comparing the reaction time (RT) between people with normal vision and people visually impaired. These works underscore how useful the warning sounds can be to improve the detectability of four-wheel electric vehicles.

At present, different countries are working on the development of new regulations related to AVAS [12, 13, 14]. First drafts define both the characteristics of the emitted noises as the traffic conditions where they must be activated. Recommendations establish the use of sounds that emulate the noise generated by ICEVs. Also, the system must remain active for speeds below $30 \mathrm{~km} / \mathrm{h}$.

The aforementioned references, both normative and scientific, refer exclusively to four-wheel vehicles. The acoustic behaviour of electric powered two-wheelers (ePTWs) has not been studied in depth. The use of motorcycles is being increased all over the world, becoming a very useful mobility tool in urban areas [15]. According to [16], it is estimated that there is a total of 313 million of two-wheel vehicles in the world. Additionally, it is foreseen that in 2040, powered two-wheelers (PTWs) represent the $35 \%$ of the total sales of vehicles [17].

According to [18], almost half of road traffic deaths take place between pedestrians, cyclists and motorcyclists. Statistically analysing the accidents occurred during the last years in which PTWs were involved, approximately the $57 \%$ of moped accidents and the $39 \%$ of accidents for high capacity motorcycles took place in urban areas [19]. One of the main causes of PTW crashes is the low visibility of the vehicle. Because of its reduced size, PTWs are often hidden by the other road users [20]. In order to ensure the safety of drivers and pedestrians, this kind of vehicles are provided with different security systems [21]. On the one hand the breaking system is enhanced using anti-lock braking systems (ABS). On the other hand, to increase the detectability of motorcycles, light-signalling devices and electronic detection equipment are introduced into the vehicle. Two-wheelers, due to their lower weight and smaller tyre-road contact surface, produce a rolling noise lower than that generated by four-wheel vehicles. Therefore, the participation of the noise emitted by the propulsion system in the overall vehicle sound will be higher. Besides, taking into account their simpler power train [22], the noise generated at low speed regimens will be given by the engine. So it is conceivable, that noise reduction due to electric propulsion systems is quite pronounced. Joël Lelong et al. in [23] analyse the acoustic behaviour of eleven motorcycles in a pass-by test at a constant speed. Vehicles had different engine capacity and one of them corresponds to a pure electric motorcycle (EM). The results showed a reduction of the sound pressure level LAmax between 10 and $15 \mathrm{dBA}$ for the electric motorcycle. According to [24], 100\% replacement of internal combustion two-wheel vehicles by electric motorcycles may involve a reduction of noise greater than $2 \mathrm{dBA}$. However, noise reduction entails a decrease on the detectability of vehicles. If we also take into consideration that the stopping distance of PTWs is higher than for four-wheel vehicles [25], the risk for drivers and pedestrians may increase significantly. In addition, PTWs with low capacity are used almost exclusively in urban areas, where speed is reduced and the problem of quiet vehicles has a greater impact.

However, not all the attention should be paid on the sound pressure level as a key factor in detectability. Sound directivity represents the directional features of a source and therefore, it plays an important role too. According to [26], the directivity index (DI) of a hemispherical source can be defined as the difference between the sound pressure level measured in a particular direction ?, and the average sound pressure level over the measurement surface. The directivity of a sound source is one of the parameters that must be considered to determine the effect of noise over a potential receiver, for instance, on traffic noise prediction models [27]. Some measurement techniques can be found on the literature to determine this parameter: stationary vehicle directivity [28]; moving sources [29]; vertical directivity for moving sources (trains [30, 31, 32], aircraft $[33,34]$, road vehicles [35]); horizontal directivity of road vehicles [36]. In order to determine the radiation pattern of the vehicles, the use of a linear microphone array during pass-by tests may be appropriate to detect the position and speed of the moving noise source [37] and therefore, to obtain the sound pressure level (SPL) for each angle suppressing background noise.

Due to the foregoing, the acoustic behaviour of PTWs in urban environments should be studied more in detail. This paper is a contribution to the acoustic study of these vehicles. The main objectives are: (1) to study the sound pressure level emitted by powered two-wheelers, comparing the noise produced by electric and internal combustion engine motorcycles (ICEM); (2) to determine the sound directivity of two-wheelers; (3) to stablish the detectability of electric and internal combustion motorcycles.

\section{Methods and materials}

\subsection{Task}

This paper examines, for a group of PTWs with different propulsion systems, the variation of the sound pressure 
level with the speed. At the same time, horizontal directivity of each vehicle was determined by means of a microphone array in a pass-by test. Finally, the detectability of PTWs was determined from an auditory test carried out in a laboratory. The following sections describe in detail the procedure used during the tests.

\subsection{Experimental Design}

A group of five mopeds with different propulsion systems was selected to be studied: three PTWs with pure electric propulsion systems - EM1, EM2 and EM3; one PTW with 4-stroke internal combustion engine - ICEM1; and one hybrid engine motorcycle (HEM) - denote during the paper as $\mathrm{HEM}_{\mathrm{EMode}}$ for electric mode and $\mathrm{HEM}_{\mathrm{ICEM} \text { ode }}$ for internal combustion mode. EM1 had a brushless DC engine with power $0.74 \mathrm{~kW}$, chain drive, a wheelbase of $1.221 \mathrm{~mm}$ and a weight of $37 \mathrm{~kg}$. The motorcycle was equipped with 24" rims and 60-507 tyres according to the European Tyre and Rim Technical Organization (ETRTO). EM2 corresponded to an electric motorcycle with a brushless permanent magnet AC engine, a maximum power of $13 \mathrm{~kW}$ and single speed direct chain drive. Its wheelbase was $1.420 \mathrm{~mm}$, with a 100/90-18 front tyre and a 120/80-17 rear tyre. This motorcycle had a weight of $147 \mathrm{~kg}$. EM3 had a brushless hub $4 \mathrm{~kW}$ engine. It had a weight of $85 \mathrm{~kg}$, a wheelbase of $1.380 \mathrm{~mm}, 13$ " rims and 130/60-13 tyres. ICEM1 consisted of a 4-stroke engine scooter of $108 \mathrm{cc}$ capacity and a weight of $114 \mathrm{~kg}$. It was provided with chain drive and had a wheelbase of $1.275 \mathrm{~mm}$. This motorcycle used a 90/90-12 front tyre and a 100/90-10 rear tyre. The hybrid motorcycle, HEM, was equipped with a Brushless DC electric motor of $1 \mathrm{~kW}$ and a $5.15 \mathrm{~kW} 4$-stroke engine. It had a weight of $130 \mathrm{~kg}$, a wheelbase of $1.240 \mathrm{~mm}$ and tyres 100/90-10 in both wheels. For HEM, the electric mode and the internal combustion mode were analysed separately, allowing to compare the behaviour of both systems with the same boundary conditions. The selected vehicles represented those low capacity motorcycles most common in urban environments. The main information regarding motorcycles has been summarised in Table I.

All PTWs were subjected to a pass-by test. To study the behaviour of the vehicles at different speeds, the tests were conducted at around 10, 20,30, 40 and $50 \mathrm{~km} / \mathrm{h}$. The actual vehicle speed was determined by means of a set of photocells located on one side of the road. During the event, the LAmax emitted by each motorcycle was measured using a Sound Level Meter B\&K Type 2250. The device was situated at $3 \mathrm{~m}$. from the traffic lane instead of the $7.5 \mathrm{~m}$. specified by the normative method (see Figure 1). This modification is intended to obtain the SPL from the pedestrian point of view in a road-crossing scenario since this is one of the situations that greater risk entail for pedestrians. At the same time, the sound directivity was measured using a linear microphone array [37]. The system was composed of 9 omnidirectional microphones, B\&K Type 4958, located perpendicularly to the track and 3 meters away from it. The microphones were connected to a multi-channel data acquisition system. All measurements took place on a traffic lane with a standard asphalt $\mathrm{G} 20+\mathrm{S} 20$.
Table I. Main features of PTWs used during the study.

\begin{tabular}{|c|c|c|c|c|}
\hline ID & $\begin{array}{c}\text { Propulsion } \\
\text { System }\end{array}$ & $\begin{array}{c}\text { Power } \\
{[\mathrm{kW}]}\end{array}$ & $\begin{array}{c}\text { Capacity } \\
\text { [cc] }\end{array}$ & $\begin{array}{l}\text { Tyre } \\
\text { Model }\end{array}$ \\
\hline ICEM1 & ICE & 5.96 & 108 & $\begin{array}{c}90 / 90-12 \\
100 / 90-10\end{array}$ \\
\hline EM1 & $\mathrm{E}$ & 0.74 & 49 & $60-507$ \\
\hline EM2 & E & 13.00 & 125 & $\begin{array}{l}100 / 90-18 \\
120 / 80-17\end{array}$ \\
\hline EM3 & $\mathrm{E}$ & 4.00 & 125 & $130 / 60-13$ \\
\hline HEM & ICE/E & $5.15 / 1$ & 125 & $100 / 90-10$ \\
\hline
\end{tabular}

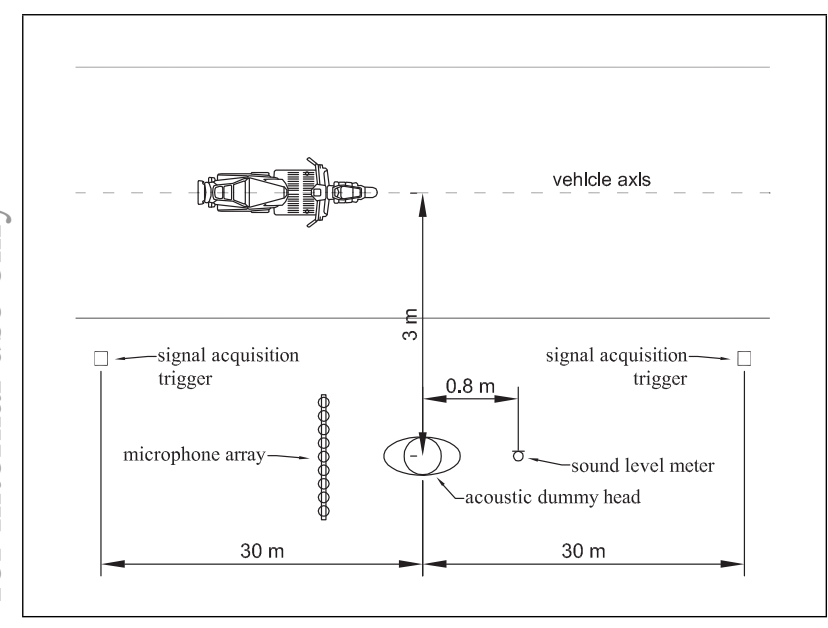

Figure 1. Pass-by test configuration.

To evaluate the detectability of PTWs, sound samples from each moped were obtained during the pass-by test. Recordings were made by means of a Head Acoustics HSM III dummy head, with a sample frequency of $44,100 \mathrm{~Hz}$ and a bit depth of 16 bits with noise shaping algorithm. A fifth order high-pass filter with cut-off frequency of $22 \mathrm{~Hz}$ was used during the acquisition. The dummy head was placed at a distance of 3 meters from the centre of the traffic lane, trying to simulate a real scenario: a pedestrian standing on the sidewalk, prepared to cross the road. The sound acquisition was made from \pm 30 meters from the dummy head. Audio samples were used during the auditory tests in order to reproduce the sound event more accurately.

\subsection{Sound directivity procedure}

Assuming that during the pass-by tests the sound pressure level of a vehicle on a fixed height was measured, the directivity of the source was referenced to the plane of emission, being the directivity changing over the angle of radiation. During the tests, all the microphones captured the signal emitted by the source with a different delay according to the position of the source and the distance to the microphone. Subsequently, all signals were processed in a Double Cross-Spectrum (time-frequency domains) in order to detect the angle of emission of the noise source and the sound pressure level at different angles of emission [23]. 
During the signal processing, two important assumptions were made: 1 ) due to the distance between the source and the microphone array, the vehicle was considered to be in the far field region for frequencies below $2 \mathrm{kHz}-$ minimum distance to far field calculated as the ratio between the squared wheelbase and four times the wavelength [38]; 2) the vehicles were moving along the track at constant speed.

\subsection{Auditory detectability}

\subsubsection{Stimuli and background noise}

As discussed in the previous section, a group of five motorcycles with different propulsion systems were measured. Table I describes the main feature of each PWT: identification (ID) during the paper (column 1); the propulsion system of each sample (column 2); the power of the engine (column 3); the capacity for ICEMs and the equivalent license capacity for EM (column 4); the weight of each motorcycle. For the HEM, electric and internal combustion modes were studied separately. Acquired sound samples were processed and conditioned to be used on the detectability tests. Samples were analysed and listened carefully in order to discard those useless. Some audio files presented different background noises that can somehow affect the validity of the samples and the detectability results: wind, birds, barking, aircraft or other vehicles. These samples were filtered or even removed. In order to eliminate a part of the signal fluctuations caused by wind, all samples were filtered by a 5-th order Butterworth highpass filter with cut-off frequency of $80 \mathrm{~Hz}$.

The binaural sound samples were obtained with an acoustic dummy head using free field equalization. This equalization allows to correct the effect of the head in the acquired signals, making possible the comparison between the measures provided by conventional microphones. To carry out the psychoacoustic tests, the free field equalization must be removed so that the signals represent accurately the event. Likewise, the use of headphones during the detectability tests may affect the accuracy of the emitted signal with respect to the real sound. The frequency response of headphones can change the spectral content of the sample and thus, must be corrected. An inverse filter from the headphones impulse response was used to solve the aforementioned effects.

The background noise used in the auditory tests was obtained overlapping the noises emitted by several idling vehicles. The resulting signal presented an equivalent sound pressure level of $61 \mathrm{dBA}$.

\subsubsection{Apparatus}

Auditory tests were performed in a room with low level of noise. A software tool was implemented to perform the detectability test. The application emitted the stored sound samples randomly, over a constant and continuous background noise, by using an external sound card TASCAM US-144MKII. Background noise was present during the whole test to avoid training effects. Sounds were presented to the listener binaurally using a high-quality reference class headphones AKG K612Pro. The level of each sample was previously checked using an acoustic dummy head (HeadAcoustics HSM III).

\subsubsection{Procedure}

An auditory test was carried out to determine the detectability of PTWs. The tests took place in a laboratory using headphones. The mopeds were presented to the listener in a pass-by mode, simulating the movement of the motorcycle in both directions. The two-wheeled vehicles approached the listener individually, at a constant speed around $20 \mathrm{~km} / \mathrm{h}$, covering a distance of \pm 30 meters from the pedestrian. In order to increase the realism of the simulation, the motorcycles were presented under the background noise conditions described in the preceding paragraph. Samples were presented individually and randomly, and the time between sound events varied between 1 and 20 seconds. Each sound was played six times - three in the left-right direction and three in the opposite - making a total of 36 sound events by subject. Listeners must indicate, by pressing a button, the moment they perceived the vehicle approaching.

\subsubsection{Participants}

A total of thirty seven volunteers (18 women and 19 men), mostly university students, took part in the auditory experiment. Participants were aged between 16 and 70 years (mean and median ages of 25.1 and 20.0 years, respectively). All the subjects declare normal hearing and vision ability. Non of the participants was an expert in the topic. The test procedure was explained to all participants, describing in detail the road-crossing scenario and the task of detecting the approaching vehicle as soon as possible and pressing a key. Different sound samples of the motorcycles were presented to the listeners before the test began.

\section{Results}

\subsection{Influence of the speed in the sound pressure level}

The analysis of the sound pressure level emitted by the tested vehicles at diverse speeds showed a significant difference between electric and internal combustion motorcycles. The results highlighted a behaviour similar to that observed on four-wheeled vehicles [39]. As the vehicles speed increases, the noise generated by aerodynamics and tyre/road contact increases. At speeds above $50 \mathrm{~km} / \mathrm{h}$, the noise produced by these phenomena had a greater contribution than noise generated by propulsion system on the total sound emitted by the vehicle. Therefore, at highspeed regimes, the sound pressure level generated by an electric moped will be similar to that produced by an internal combustion model. Figure 2 shows the evolution of the sound pressure level for each PTW according to speed. Due to engine limitations, some vehicles did not reach speeds above $45 \mathrm{~km} / \mathrm{h}$. For the HEM running in electric 


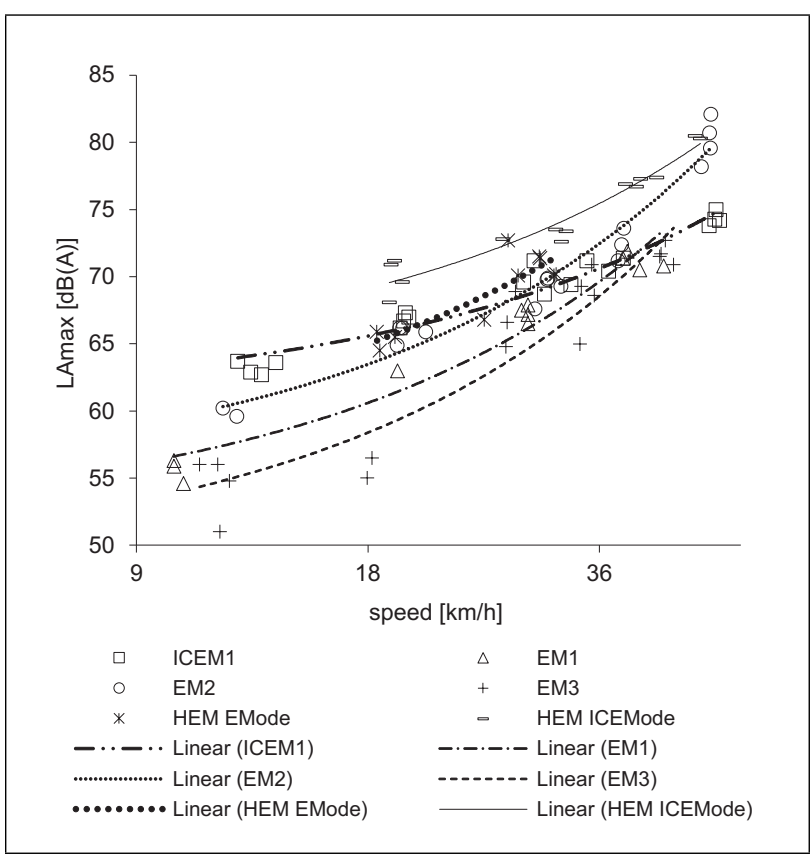

Figure 2. Sound Pressure Level against speed for the different PWTs. The lines represent the linear trend lines.

mode, the speed was limited at around $30 \mathrm{~km} / \mathrm{h}$ by the control unit.

At speeds below $20 \mathrm{~km} / \mathrm{h}$ the LAmax emitted by the electric motorcycles was lower than that obtained for motorcycles with internal combustion propulsion system (ICEM1, HEM ICEMode). Around $20 \mathrm{~km} / \mathrm{h}$, there was practically no difference in LAmax between EM2, HEM EMode and ICEM1 (1dBA). However, between ICEM1-EM1 and ICEM1-EM3, the difference in SPL was 4 and $8 \mathrm{dBA}$ respectively. At $13 \mathrm{~km} / \mathrm{h}$, the difference in LAmax for ICEM 1 and EM 3 was $9 \mathrm{dBA}$. At $40 \mathrm{~km} / \mathrm{h}$ the difference was reduced to less than $1 \mathrm{dBA}$ regarding ICEM1.

A spectrum analysis showed the appearance of harmonic frequencies in electric motorcycles (see Figure 3). This behaviour was observed for all electric motorcycles at speeds above $20 \mathrm{~km} / \mathrm{h}$. These tonal components were linked to the vehicle speed, changing their value as the velocity increases. The existence of tonal components may result in an increase of the annoyance perceived by drivers and pedestrians [40]. Clear harmonic frequencies were not found for motorcycles powered by internal combustion engines, ICEM1 and HEM ICEMode (see Figure 4).

\subsection{Horizontal directivity}

The global sound pressure level radiated for each PTW during the pass-by tests in the frequency range from 350 to $2800 \mathrm{~Hz}$ was analysed at around $20 \mathrm{~km} / \mathrm{h}$ (see Figure 5). As already concluded in the previous section, the SPL generated by ICE motorcycles was generally higher than the levels obtained from EMs. Signals were analysed in terms of directivity at three different octave bands: $500 \mathrm{~Hz}$, $1000 \mathrm{~Hz}$ and $2000 \mathrm{~Hz}$. For motorcycles powered by internal combustion engines, ICEM1 and HEM ICEMode, $_{\text {, the di- }}$ rectional effect of tyre-road noise was reduced due to the

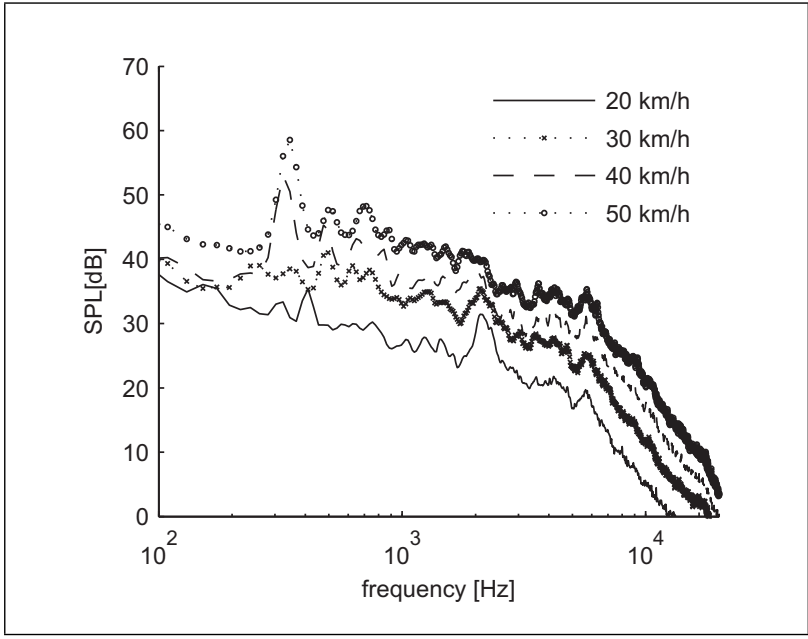

Figure 3. Evolution of the frequency spectrum with the speed for EM2.

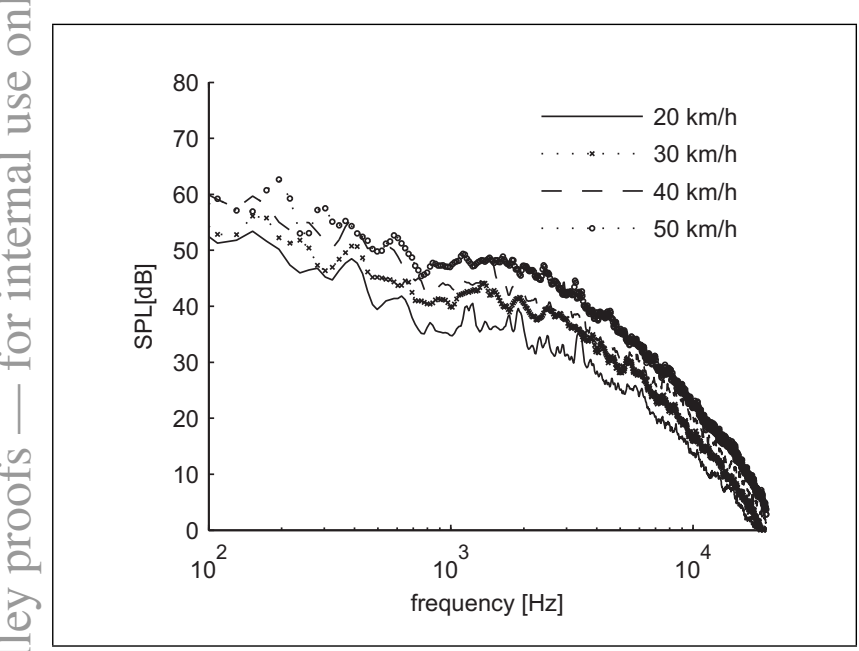

Figure 4. Evolution of the frequency spectrum with the speed for ICEM1.

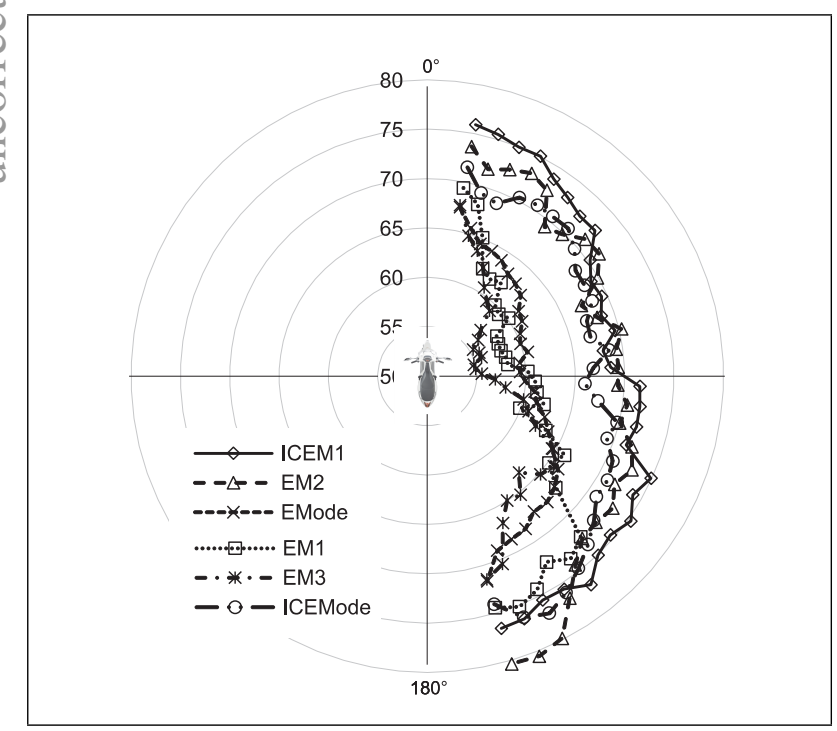

Figure 5. Global sound pressure level, in the frequency range from 350 to $2800 \mathrm{~Hz}$, at around $20 \mathrm{~km} / \mathrm{h}$ depending on the angle. 


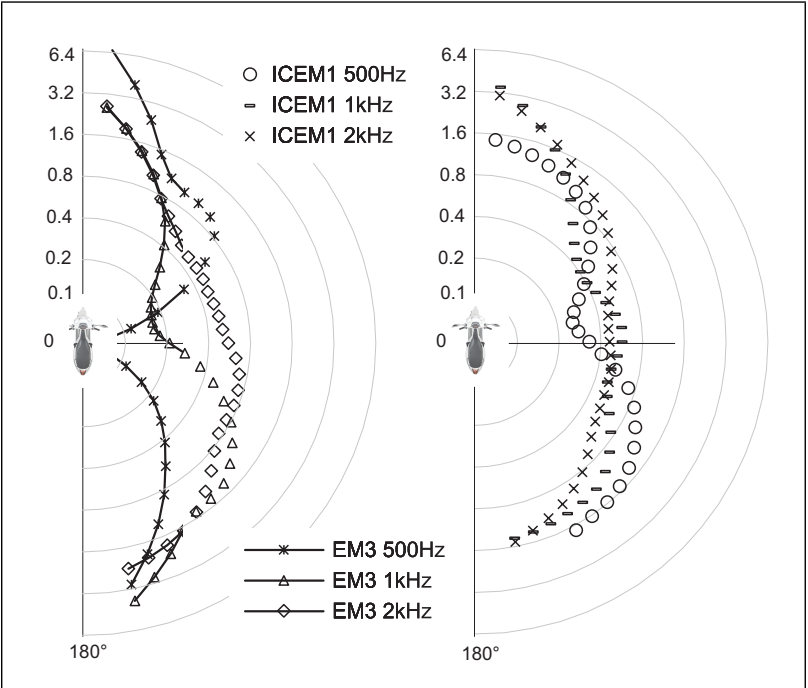

Figure 6. Directivity factor Q comparison between ICEM1 (right) and EM3 (left) at around $20 \mathrm{~km} / \mathrm{h}$. At low frequencies, the EMs analysed showed very similar directivity factor values for the front and rear of the vehicle, and lower on the central part (angle of $90^{\circ}$ ).

masking effect caused by the mechanical sound radiated by the engine.

The directivity factor $\mathrm{Q}$, defined as the ratio between the square pressure in a certain angle and the average of the square pressures in all directions, was analysed. Figure 6 shows the $\mathrm{Q}$ values obtained for two tested motorcycles with different propulsion system, ICEM1 and EM3. At low frequencies, EM3 presented a radiation pattern significantly more directive than ICEM1. At high frequency bands, Q values obtained for both propulsion systems become more similar.

This behaviour resulted in more directive radiation patterns. On the contrary, horizontal directivity for motorcycles ICEM1 and HEM ICEMode, both equipped with a combustion engine, showed a dissymmetry between the front and rear of the vehicle. This phenomenon was due to the exhaust pipe and similar results were found in [23]. The HEM used in this research was a clear example of this effect. HEM running in ICE mode had, for angles above $140^{\circ}$, a directivity factor higher than in electric mode (see Figure 7).

Figure 8 shows the maximum DI for EM3 for the angles from $0^{\circ}$ to $90^{\circ}$ (angular sector consider as the most sensitive for pedestrians), at speeds between 20 and $50 \mathrm{~km} / \mathrm{h}$, for 500,1000 and $2000 \mathrm{~Hz}$ octave bands. The values of DI were obtained from the average of different iterations carried out during the pass-by test at the same speed. The results showed a progressively decrease of the directivity with the speed of the vehicle. The approximation of the data with a second-order polynomial function provided correlation values over $90 \%$.

\subsection{Auditory Detectability Test}

\subsubsection{Descriptive results}

During the auditory test, each sound was played six times - three in the left-right direction and three in the opposite.

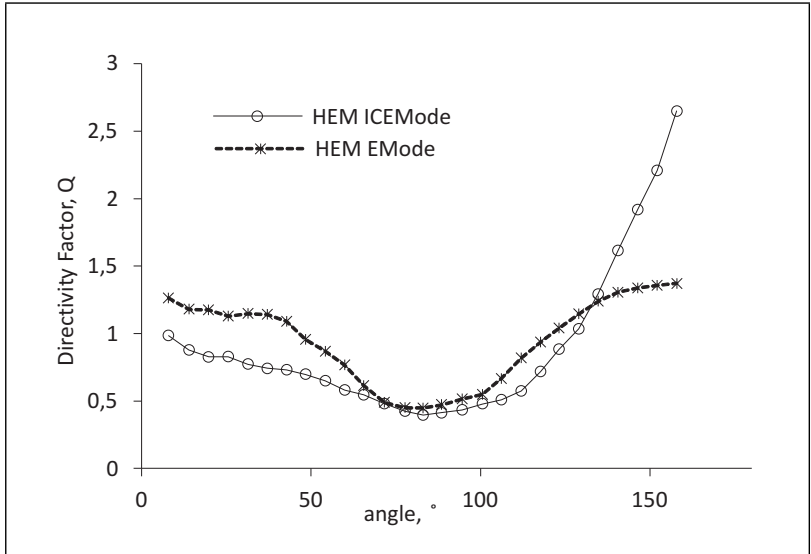

Figure 7. Directivity factor $\mathrm{Q}$ for the hybrid motorcycle at $20 \mathrm{~km} / \mathrm{h}$ and $500 \mathrm{~Hz}$ octave band.

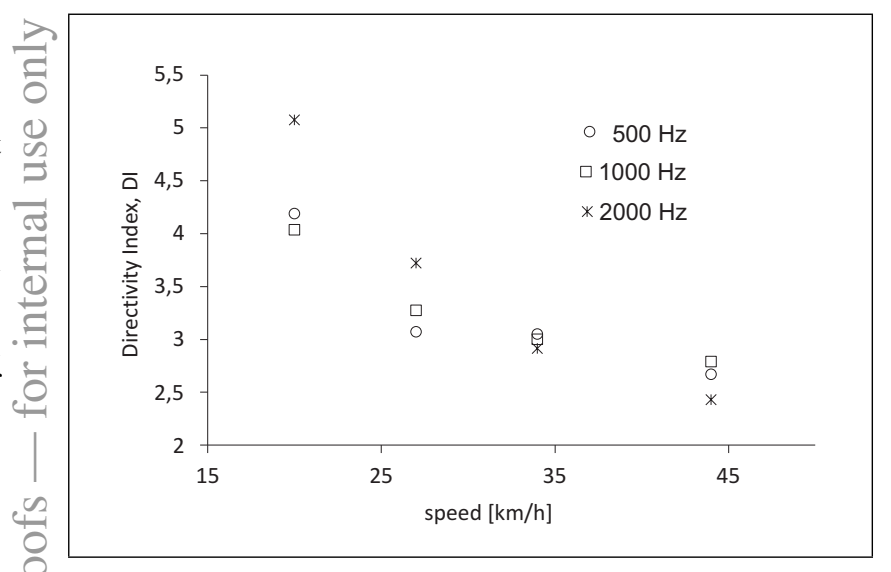

Figure 8. Directivity Index of EM3 at different speeds and octave bands. Maximum value, calculated for the angles from $0^{\circ}$ to $90^{\circ}$.

In order to analyse data globally, the influence of the direction motion into the reaction time was studied. The results revealed that direction motion had no significant influence on the listener reaction time: $\mathrm{t}(36)=0.01, \mathrm{p}=0.99>0.05$. Data obtained in both directions were collapsed for subsequent analysis.

Some participants committed errors in the detection of some vehicles. At times, detections took place once the listener had been run over, which produced negative distances to pedestrian in the test results. Some other times, subjects did not press the corresponding key during the test, so the time value for the sample was lost. The two situations described above were considered errors and treated in the same manner. The percentage of errors on the total detections was $3.25 \%$. Analysing vehicles depending on their propulsion system, detection errors represented $2.25 \%$ for ICEM and $3.60 \%$ for EM (see Figure 9). Data concerning errors committed depending on the type of propulsion system did not comply the requirements for a parametric analysis of variance (ANOVA) test. LeveneŠs test indicated unequal variances $(F(1,220)=6.432$, $\mathrm{p}=0.012<0.05)$. Also, Shapiro-Wilk test showed that errors did not follow a normal distribution $\left(\mathrm{W}_{\text {ICEM }}(74)\right.$ $=0.392, \mathrm{p}<0.05$; $\mathrm{EM}(148)=0.440, \mathrm{p}<0.05)$. Non- 


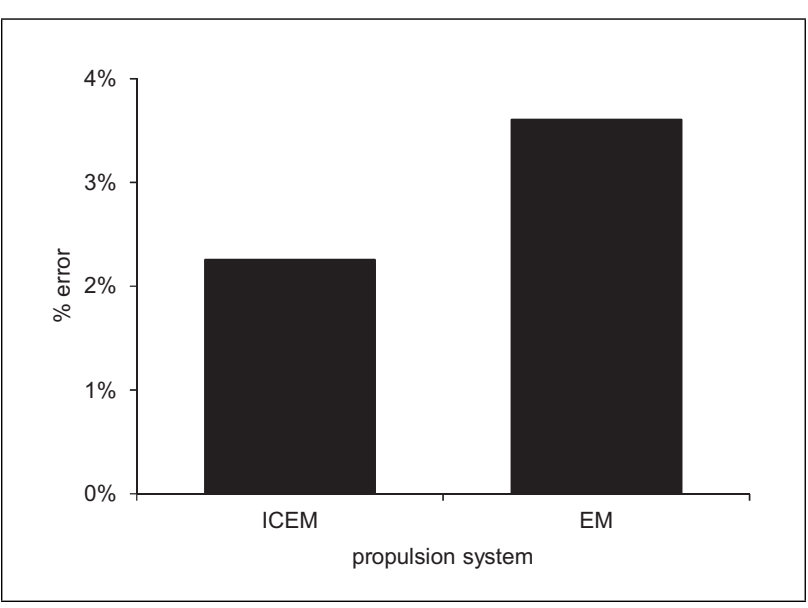

Figure 9. Detection errors depending on the propulsion system.

parametric method was used to determine the significance of propulsion system into the errors committed by subjects. Kruskal-Wallis $\mathrm{H}$ test showed that there was no statistically significant difference in detection errors between different propulsion systems, $\chi^{2}(1)=0.782, \mathrm{p}=0.376>$ 0.05 .

According to non-parametric Kruskal-Wallis $\mathrm{H}$ test, there was a statistically significant difference between all models, $\chi^{2}(5)=45.456, \mathrm{p}<0.05$, analysing errors by motorcycles (see Figure 10). A pairwise comparison porthoc test showed that there is statistically significant difference between EM3 and the remaining stimuli $\left(\mathrm{t}_{1 \_4}(1)\right.$ $=-46.324, \mathrm{p}_{\text {adj }}<0.05 ; \mathrm{t}_{2 \_4}(1)=-52.081, \mathrm{p}_{\mathrm{adj}}<0.05$; $\mathrm{t}_{3 \_4}(1)=-43.014, \mathrm{p}_{\mathrm{adj}}<0.05 ; \mathrm{t}_{5 \_4}(1)=52.081, \mathrm{p}_{\text {adj }}<$ $0.05 ; \mathrm{t}_{6 \_4}(1)=37.257, \mathrm{p}_{\text {adj }}<0.05$; where $\mathrm{p}_{\text {adj }}$ denotes p-values adjusted using Bonferroni method). Figure 10 shows the percentage of error for each PTW. Reaction times associated with erroneous detections were removed for further analysis.

Global reaction time represented a normal distribution with $\mathrm{M}=3.09 ; \mathrm{SD}=0.57 ; \mathrm{CV}=18 \%$ (Figure 11).

Analysing the reaction times by motorcycle, a LeveneŠs test indicated unequal variances $(\mathrm{F}(5,215)=5.444, \mathrm{p}<$ $0.05)$. In the same way, data concerning reaction times by propulsion system presented unequal variances $(\mathrm{F}(1,219)$ $=28.618, \mathrm{p}<0.05)$. Data violated the assumptions of normality and homoscedasticity necessary to implement parametric analysis methods and therefore, results were statistically analysed by a non-parametric Kruskal-Wallis $\mathrm{H}$ test.

\subsubsection{Influence of propulsion system in auditory reac- tion time}

As indicated in paragraph 3.3.1., reaction times by propulsion system did not comply the requirements of normality and homoscedasticity needed to apply the parametric ANOVA test. In this case, non-parametric tools were used to study the relationship between propulsion system and the reaction time. The Kruskal-Wallis $\mathrm{H}$ test showed that there was a statistically significant difference in reaction time between propulsion systems, $\chi^{2}(1)=121.848, \mathrm{p}<$

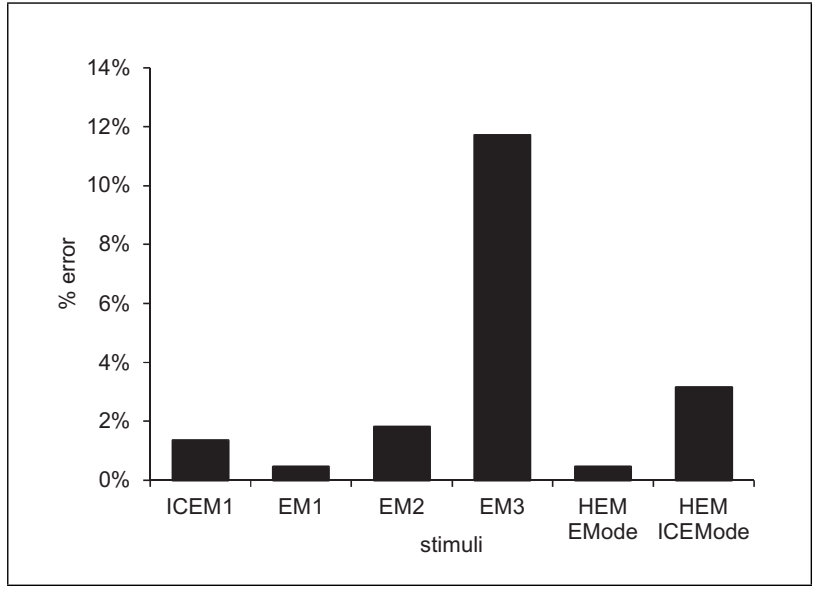

Figure 10. Detection errors depending on the PTW.

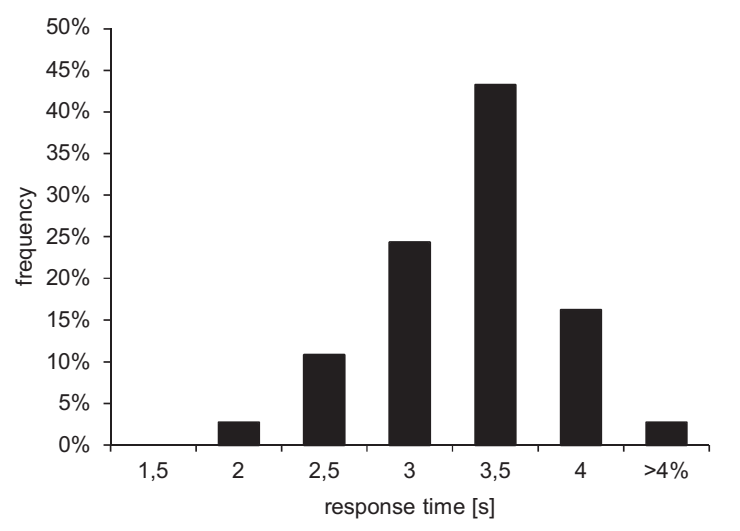

Figure 11. Distribution of mean overall reaction times of all subjects and vehicles.

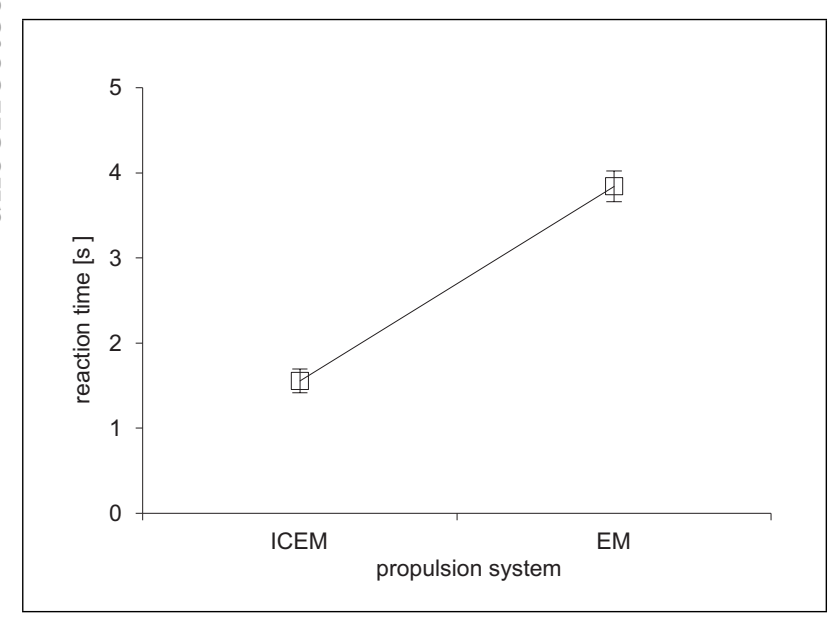

Figure 12. Mean reaction time depending on the propulsion system.

0.05. As shown in Figure 12, mean reaction time for EM was higher than ICEM one $\left(\mathrm{RT}_{\mathrm{EM}}=3.84 \mathrm{~s} ; \mathrm{RT}_{\mathrm{ICEM}}=\right.$ $1.55 \mathrm{~s})$. Given the speed of motorcycles $(19 \pm 1 \mathrm{~km} / \mathrm{h})$, the difference supposed a spatial distance of $12 \mathrm{~m}$. 
Table II. Statistical descriptors. Mean Reaction Times. Lower/ Higher: Lower/Higher limit of the $95 \%$ confidence interval for the mean.

\begin{tabular}{|l|ccc|}
\hline PTW & RT Mean & Lower & Higher \\
\hline ICEM1 & 1.857 & 1.594 & 2.120 \\
EM1 & 3.447 & 3.163 & 3.731 \\
EM2 & 2.877 & 2.612 & 3.142 \\
EM3 & 5.031 & 4.811 & 5.252 \\
HEM $_{\text {EMode }}$ & 4.011 & 3.738 & 4.284 \\
HEM $_{\text {ICEMode }}$ & 1.284 & 1.179 & 1.389 \\
\hline
\end{tabular}

\subsubsection{Differences between powered two wheelers}

This section analyses the influence of the vehicles in the reaction time of the subject. Reaction times obtained for HEM $_{\text {ICEMode }}$ presented a standard error significantly lower than other motorcycles. This resulted in a lower variance and a narrower $95 \%$ confidence interval for the mean (see Table II). Non-parametric methods were used to analyse the data.

The Kruskal-Wallis $\mathrm{H}$ test showed that there was a statistically significant difference in reaction time between motorcycles, $\chi^{2}(5)=164.700, \mathrm{p}<0.05$. A pairwise comparison post-hoc test showed that there is no statistically significant difference between ranges for some motorcycles as show in Figure 13.

Figure 13 shows the mean reaction time obtained for each motorcycle. According to the statistic results, there was a significant difference between ICEMs (including HEM $_{\text {ICEMode }}$ ) and EMs. Motorcycles with electric propulsion system resulted in higher reaction times, which means a higher risk of crash for pedestrians. In accordance with the results obtained in Section 3.3.1., vehicle with higher reaction time lead to greatest number of detection errors.

Kruskal-Wallis $\mathrm{H}$ test showed that there was no significant difference between reaction times for the different groups of ages described in paragraph 3.3.1., $\chi^{2}(2)=$ $4.006, \mathrm{p}=0.135>0.05$.

The maximum difference in the reaction time between motorcycles was $3.74 \mathrm{~s}$, which corresponded to a distance of $19.97 \mathrm{~m}$ (vehicle speed during the test of around $19 \mathrm{~km} / \mathrm{h}$ ). The minimum time difference between electric and internal combustion motorcycles was 1 second, which means a distance of 7 meters. Figure 14 shows the mean distance between PTW and pedestrian at the time of detection. Electric vehicles were detected at a shorter distances from the pedestrian. According to [25], at $19 \mathrm{~km} / \mathrm{h}$ the stopping time for a motorcycle is $0.58 \mathrm{~s}$, which represents a stopping distance of approximately $3 \mathrm{~m}$. Considering the reaction time of the driver $(0.75 \mathrm{~s}-3.96 \mathrm{~m})$, the total stopping distance for a motorcycle running at a speed of $19 \mathrm{~km} / \mathrm{h}$ will be $7 \mathrm{~m}$. This distance sets the safety limit for pedestrian since, although the driver detected his presence, he would not have time to stop the motorcycle. The safety limit will depend on driver attention, the road surface, the weather conditions and the condition of the vehicle at the time. Thus, moped EM3 represented a real risk for pedestrians. In this case, the PTW was detected at

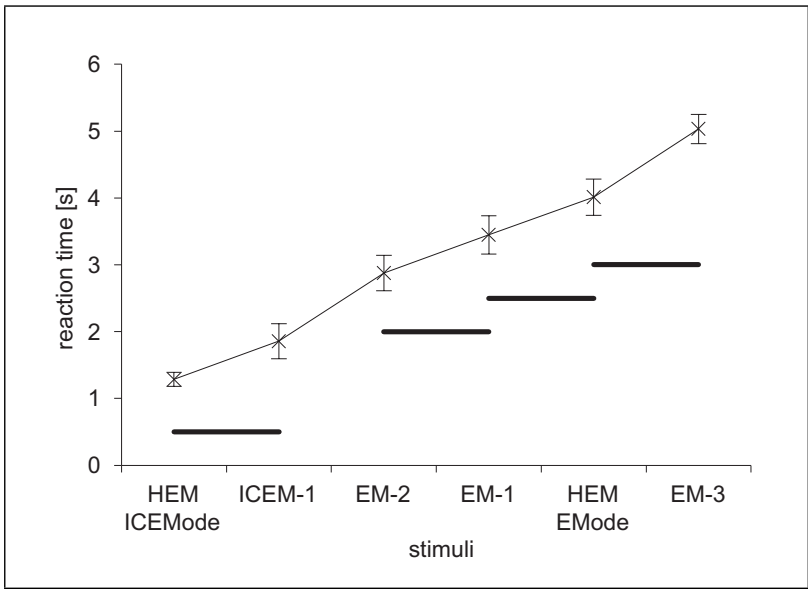

Figure 13. Mean reaction time depending on the PTW. Horizontal lines denote pairs with no statistically significant difference.

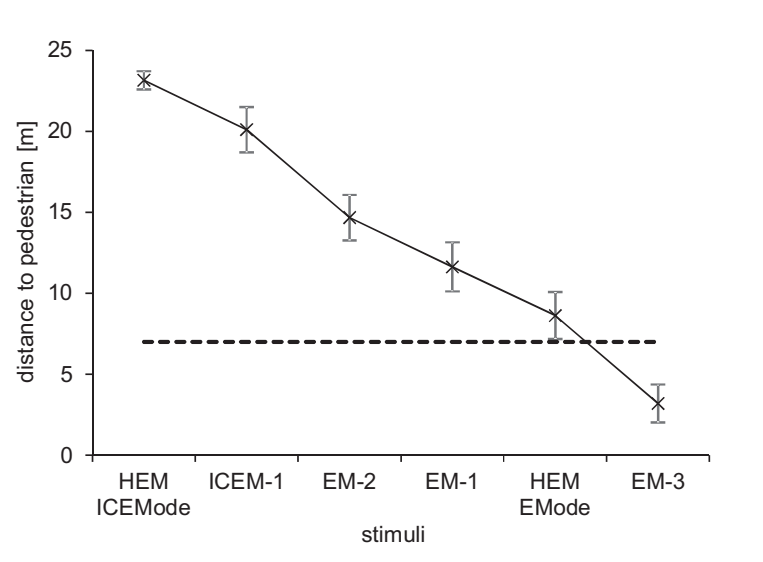

Figure 14. Distance in meters at which the observer detected the vehicle. Dotted line represents unsafe distance calculated as describe in paragraph 3.3.2.

a distance under the minimum safety distance $\left(\mathrm{RT}_{\mathrm{EM} 3}=\right.$ $5.03 \mathrm{~s} ; \mathrm{DP}_{\mathrm{EM} 3}=3.18 \mathrm{~m}$ ). Similarly, the hybrid motorcycle running in electric mode was detected close to the limit lower limit of $95 \%$ confidence interval for the mean equal to $7.17 \mathrm{~m}$. An increase of the equivalent sound pressure level of the background noise used during the tests should result in an increase of the reaction times.

Analysing the temporal history of SPL for each motorcycle during the pass-by test, it is possible to stablish a detection threshold at which the vehicles were detected by pedestrians. The comparison between the threshold obtained for all the motorcycles showed a maximum difference of $3.4 \mathrm{dBA}$ :

\section{ICEM1, $51.4 \mathrm{dBA} ; \quad$ HEM $_{\text {EMode }}, 54.8 \mathrm{dBA}$.}

Figure 15 highlights how the detection for both propulsion systems available on the hybrid motorcycle took place practically at the same level (difference less than $1 \mathrm{dBA}$ ). As evidenced in [10], the detection threshold will be significantly affected by the background noise. 


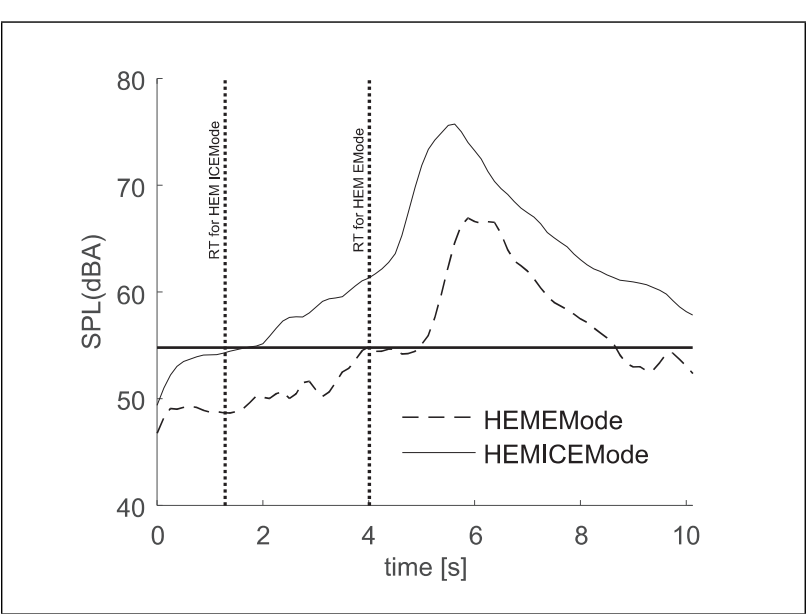

Figure 15. Time history of sound pressure level during the passby test for the hybrid motorcycle. The horizontal line denotes the detection threshold for both propulsion systems.

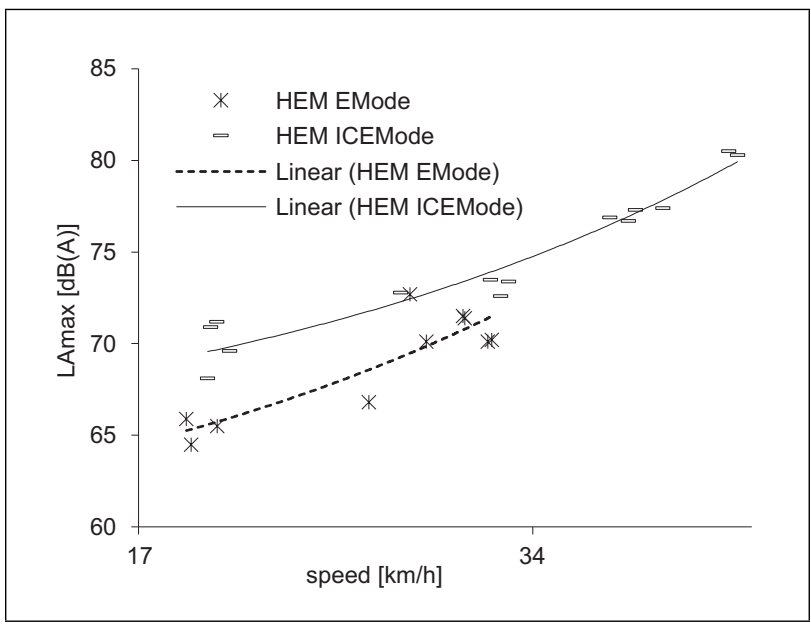

Figure 16. SPL depending on the speed for a hybrid motorcycle.

\subsection{Hybrid electric powered two-wheelers}

In order to compare different propulsion systems with the same boundary conditions, a hybrid electric motorcycle was studied. This kind of PTW allowed to activate or deactivate the electric mode by pressing a button. This facilitated to perform measurements in a certain speed range - 18 to $30 \mathrm{~km} / \mathrm{h}$ - with both propulsion systems. Above $30 \mathrm{~km} / \mathrm{h}$, the motorcycle automatically switch off the electric engine and turn on the ICE mode.

Analysing the emitted noise of the PTW running in each mode, ICE mode presented a sound pressure level $7 \mathrm{dBA}$ higher than the electric mode at $20 \mathrm{~km} / \mathrm{h}$ (see Figure 16). The difference decreases as the speed increases, obtaining a gap of $4.5 \mathrm{dBA}$ at $30 \mathrm{~km} / \mathrm{h}$. This behaviour was due to the fact that as the speed increases, the noise produced by the tyre-road contact and the aerodynamics of the motorcycle becomes more relevant in the overall noise. So, at higher speeds, the level of noise emitted by the motorcycles was equal for both propulsion systems.

The difference between both systems was reflected too in a detectability delay of approximately $2.7 \mathrm{~s}$, which cor- responds to a distance of about $14.5 \mathrm{~m}\left(\mathrm{RT}_{\text {HEM_ICEMode }}=\right.$ $1.28 \mathrm{~s} ; \mathrm{RT}_{\text {HEM_EMode }}=4.01 \mathrm{~s}$ ). The results confirmed how the propulsion system affects the vehicle detectability. The Kruskal-Wallis $\mathrm{H}$ test showed that there was a statistically significant difference between the reaction time for both propulsion systems, $\chi^{2}(1)=53.515, \mathrm{p}<0.05$.

\section{Discussion}

The current study analyses the acoustic behaviour of powered two-wheelers with different propulsion systems and determine the risk for pedestrians on the approach of an electric PWT at $20 \mathrm{~km} / \mathrm{h}$. For this, a pass-by test was carried out on a total of 5 motorcycles. The sound pressure level and the horizontal directivity of each vehicle were analysed at different speeds. To analyse the detectability of motorcycles at $20 \mathrm{~km} / \mathrm{h}$, an auditory test was carried out in a laboratory. Sound samples used were obtained during the pass-by tests by means of an acoustic dummy head. Auditory tests were conducted on a total of 37 people, mostly students.

The results revealed a significant difference between the sound pressure level generated by the electric and internal combustion motorcycles at low speeds (approximately $9 \mathrm{dBA}$ at $13 \mathrm{~km} / \mathrm{h}$ ) as in [23]. As the velocity of the vehicle increased, the difference between both propulsion systems was reduced (approximately $1 \mathrm{dBA}$ at $40 \mathrm{~km} / \mathrm{h}$ ). At high speeds, the noise produced by aerodynamics and the tyreroad contact resulted more significant and hence, noise produced by all vehicles became equal. At the same time, the absence of mechanical engine noise for EMs resulted in a more directive radiation patterns. In the same way as [23], those motorcycles provided with internal combustion engine showed a dissymmetry in the horizontal directivity between the front and rear of the vehicle. This effect was mainly due to the exhaust pipe. On the other hand, the relationship between speed and directivity was studied. In accordance with the results, an increase in the speed carries to a decrease in the maximum directivity index of the motorcycle calculated for the angles from $0^{\circ}$ to $90^{\circ}$.

The difference in level observed at low speed resulted in a decrease of the detectability for electric vehicles. Motorcycle EM3 was detected at a mean distance from the pedestrian of $3.18 \mathrm{~m}$. This distance was less than the safety limit set by the stopping distance of the vehicles. The difference in the mean reaction time for internal combustion engine and electric motorcycles was $2.3 \mathrm{~s}$ (ICEM1 and EM2). Therefore, there is a real risk for pedestrians because of the incorporation of this kind of vehicles to the urban traffic. It should be noted that the difference between reaction times resulted for a hybrid moped in both operating modes (electric and internal combustion engine) was over 10 meters. Besides, it was observed a significant relationship between directivity and detectability for PTWs.

The temporal history of SPL during the pass-by test allowed to obtain a detection threshold for each motorcycle. A comparison of all of them revealed a maximum difference in the detection level of $3.4 \mathrm{dBA}$. For the hybrid mo- 
torcycle, the difference was less than $1 \mathrm{dBA}$ between the two propulsion systems.

The results shown in this study were obtained under specific background noise conditions. The use of other surroundings, like the use of urban environment with higher levels of noise, should result in a decrease of reaction times and even could involve the non-detection of some of the tested vehicles. According to the results, the need of an alerting system in two-wheeled vehicles must be considered.

\section{References}

[1] Clean Energy Ministerial: Global EV outlook, understanding the electric vehicle landscape to 2020. April 2013.

[2] Clean Energy Ministerial: Global EV outlook. Update, 2015.

[3] J. Lelong, R. Michelet: Passenger cars. Power unit and tyreroad noise, driving behaviour: what are the stakes? Proc. Internoise, The Hague, 2001, 135-138.

[4] I. Old, K. Kaliski, L. Blomberg: Sound emissions from a plug-in electric vehicle. Proc. Internoise, New York, 2012.

[5] C. Cai: Noise emission from electric cars. Master's thesis. Department of Electrical Engineering. Acoustic Technology (ACT). Technical University of Denmark, Kgs. Lyngby, Denmark, July, 2012.

[6] Burden of disease from environmental noise. Quantification of healthy life years lost in Europe. World Health Organization, Regional Office for Europe, 2011, JCR64428.

[7] L. Garay-Vega, J. Hastings, A. anf Pollard, M. Zuschlag, S. M.: Quieter cars and the safety of blind pedestrians: Phase I, report dot hs 811 304. Tech. rep., National Highway Traffic Safety Administration, U.S. Department of Transportation, April 2010.

[8] E. Altinsoy: The detectability of conventional, hybrid and electric vehicles sounds by sighted, visually impaired and blind pedestrians. Proc. Internoise, Innsbruck, 2013.

[9] C. C. W. J, R. Austin: Incidence rates of pedestrian and bicyclist crashes by hybrid electric passenger vehicles: an update, dot hs 811 526. Annals of Emergency Medicine 64 (2014) 195-196.

[10] K. Yamauchi, D. Menzel, M. Takada, K. Nagahata, S. Ichro Iwamiya, H. Fastl: Psychoacoustic examination of feasible level of additional warning sound for quiet vehicles. Acoust. Sci. \& Tech. 36 (2015) 120-125.

[11] E. Parizet, W. Ellermeier, R. Robart: Auditory warnings for electric vehicles: Detectability in normal-vision and visually-impaired listeners. Applied Acoustics 86 (2014) $50-58$.

[12] G. Dalrymple: Minimum sound requirements for hybrid and electric vehicles. Tech. Rep. NHTSA-2011-0148, National Highway Traffic Safety Administration, 2011.

[13] Ministry of Land, Infrastructure, Tourism: Japanese activities on approaching vehicle audible system for HEVs and EVs. Tech. rep., May 4th 2010.

[14] I. Roudard: Proposal for a European parliament and council regulation on community design (94/c 29/02). COM (93) 342 final - COD 463 (submitted by the commission on 3.12.93) proposal for a European parliament and council directive on the legal protection of designs (93/c 345/09) COM (93) 344 final - COD 464, Computer Law \& Security Review 10 (1994) 26-31, COM (2011) 856. doi:10.1016/0267-3649(94)90135-x.
[15] P. Van Elslande, V. Feypell-de la Beaumelle, J. Holgate, et al.: Mobility and safety of powered two-wheelers in the OECD countries. Transport Research Arena 2014, Paris.

[16] N. Rogers: Trends in motorcycle fleets worldwide. International Transport Forum. Organisation for Economic CoOperation and Development. Workshop on Motorcycling safety, Lillehammer, June 2008.

[17] J. MacDonald: Bloomberg new energy finance. 01/08/2016 http://about.bnef.com.

[18] World Health Organization: Global status report on road safety. 2015.

[19] European Commission: European road safety observatory. Annual Accident Report, 2015.

[20] R. Krautscheid, J. Krzywinski: Conspicuity of poweredtwo wheelers. Bast. ISAL, 2009.

[21] E. Bastiaensen: The shared road to safety - A global approach for safer motorcycling. International Transport Forum, Leipzig, 2014.

[22] P. D. Walker, H. M. Roser: Energy consumption and cost analysis of hybrid electric powertrain configurations for two wheelers. Applied Energy 146 (2015) 279-287.

[23] J. Lelong, R. Chatagnon, C. Clerc, D. Jamin, M. Seigner, M. Thivant: Towards a reduction of noise emission of powered two-wheels. Part 1. Inter-noise 2014. 43rd International Congress on Noise Control Engineering: Improving the World Through Noise Control, Melbourne, Australia, 2014.

[24] N. Sheng, X. Zhou, Y. Zhou: Environmental impact of electric motorcycles: evidence from traffic noise assessment by building - based data mining technique. Science of The Total Environment. DOI: 10.1016/j.scitotenv.2016.02.148, March 2016.

[25] D. Hough: Proficient motorcycling - the ultimate guide to riding well. BowTie Press, USA, ISBN 1-889540-53-6 (2008 2nd ed. ISBN 978-1-933958-35-4).

[26] BS EN ISO 3744: Acoustics. Determination of sound power levels and sound energy levels of noise sources using sound pressure. Engineering methods for an essentially free field over a reflecting plane. United Kingdom, 2010.

[27] R. Peral, I. H. Flindell, J. Alberola, J. M. Marín: Measuring the directivity of road vehicles moving at high speeds. Internoise 2004, Prague, Czech Republic, August 2004.

[28] J. Chatillon: Influence of source directivity on noise levels in industrial halls: Simulation and experiments. Applied Acoustics 68 (2007) 682-698.

[29] B. M. Favre, B. T. Gras: Noise emission of road vehicles: Reconstitution of the acoustic signature. Journal of Sound and Vibration 93 (1984) 273-288.

[30] C. H. Chew: Vertical directivity of train noise. Applied Acoustics 51 (1997) 157-168.

[31] C. H. Chew: Vertical directivity pattern of a train noise. Applied Acoustics 55 (1998) 243-250.

[32] X. Zhang, H. G. Jonasson: Directivity of railway noise sources. Journal of Sound and Vibration 293 (2006) 9951006.

[33] C. Asensio, I. Pavon, M. Ruiz, R. Pagan, M. Recuero: Estimation of directivity and sound power levels emitted by aircrafts during taxiing, for outdoor noise prediction purpose. Applied Acoustics 68 (2007) 1263-1279.

[34] C. Asensio, I. Pavon, M. Ruiz, R. Pagan, M. Recuero: Aircrafts' taxi noise. Sound power level and directivity frequency band results. Applied Acoustics 70 (2009) 9861008. 
[35] D. S. Cho, S. Mun: Determination of the sound power levels emitted by various vehicles using a novel testing method. Applied Acoustics 69 (2008) 185-195.

[36] Y. Mori: Noise directivity of vehicles on actual road. Proceedings of Internoise-99, Florida, 1999.

[37] R. Peral-Orts, E. Velasco-Sanchez, N. Campillo-Davo, H. Campello-Vicente: Using microphone arrays to detect moving vehicle velocity. Archives of Acoustics 38 (2013) 407-415.
[38] L. E. Kinsler, A. R. Frey, A. B. Coppens, J. V. Sanders: Fundamentals of acoustics. 4th ed. John Wiley \& Sons, New York, 1982.

[39] G. Marbjerg: Noise from electric vehicles - a literature survey. Report within Compett project, April, 2013.

[40] E. Parizet, A. Bolmont, S. Fingerhuth: Subjective evaluation of tonalness and relation between tonalness and unpleasantness. Proc. Internoise, Ottawa, 2009. 